\title{
ARTICLE
}

\section{Person-centred care: Bridging current models of the clinician- patient relationship}

\author{
Stephen Buetow PhD \\ Associtate Professor, Department of General Practice and Primary Health Care, University of Auckland, \\ Auckland, New Zealand
}

\begin{abstract}
Modern medicine threatens the ability of the clinician and the patient to care, and be cared about as whole, human individuals in health care. However, the interests of patients are put behind those of the population and, on the authority of professionalism and patient-centred care, ahead of those of clinicians. This situation has prompted the development of new models of the clinician-patient relationship: relationship-centred care, care as a 'window mirror' and person-centred care. From my own vantage in primary care, this paper will discuss each of these models against the backdrop of so called patient-centred care. This comparison will apply a common standard that differentiates light from shadow, both as physical phenomena that represent images in the world and as concepts that indicate what is present beyond representation. I conclude that at least in continuing clinician-patient relationships, which still characterize primary care, person-centred care maximizes the range of illumination in which clinicians and patients can be seen as individuals in social interaction.
\end{abstract}

\section{Keywords}

Physician-patient relations, Persons, Patient-centred care, Delivery of health care, Primary health care

\section{Correspondence Address}

Dr. Stephen Buetow, Department of General Practice and Primary Health Care, University of Auckland, Private Bag 92019, Auckland Mail Centre, Auckland 1142, New Zealand. E-mail: s.buetow@auckland.ac.nz

Accepted for publication: 15 February 2011

\section{Introduction}

The clinician-patient relationship is an important indicator of the quality of care, especially at this juncture in history as biomedicine [1], epidemiology [2] and population-based health care [3] threaten to overshadow the ability of the clinician and patient to care, and be cared about, as people. Clinicians have become expected, in this milieu, to act as technocratic managers who are told to put patients first, yet also to conflate patients and their diseases and to act for the common good, in general on the biostatistical basis of population averages. These scientistic and collectivistic foci have obscured the totality of patients as whole, ignoring their reality as human individuals, by putting their interests behind those of their populations [4]. In turn, the interests of patients have been put ahead of those of clinicians $[5,6]$ by the dominant models of professionalism [11], consumerism and patient-centred care [7-9].

Each of these practices of favouring one set of interests over another has been predicated on perceived differences between the interests. However, the differences weaken upon recognizing that each set of interests is interwoven and interdependent. For example, if clinicians who neglect themselves are in a poor position to care for their patients, then the good of the clinician cannot be secondary to that of the patient [10]. There appears a need therefore to temper the language of priority and focus on how care can assert and satisfy the human interests of each and every patient and clinician in the context of the population(s) of which they are part. Progress toward meeting this need has been made in disciplines such as primary care, where continuing clinician-patient relationships facilitate the co-production of a broad, coordinated range of services [11]. And thus we can discern the emergent development of new models of the clinician-patient relationship: relationship-centred care [12], care as a 'window mirror' [10] and person-centred care $[13,14]$.

This paper compares these individual models against the backdrop of so-called patient-centred care. To facilitate this comparison, I apply a common standard one that differentiates light from shadow, where shadow is defined as an absence of light under conditions that make

The International Journal of Person Centered Medicine Volume 1 Issue 1 pp 196-203 
that absence visible [15]. The distinction between light and shadow provides a way of seeing and understanding each of the models. However, it transcends a grasping of light and shadow as physical phenomena that represent images in the world by treating them also as concepts of what is accessible beyond representation [16]. In this context I will discuss, in turn, the models of patient-centred care, relationship-centred care, care as a 'window mirror'[10] and person-centred care. From my own vantage in primary care, this paper's discussion will critique the ability of each model to describe the caring that should take place, especially within individual clinician-patient relationships that continue over time.

\section{Patient-centred care}

The professionalism of doctors has been defined as emphasizing the primacy of the welfare of the patient [5]. A recent consensus statement, endorsed by a consortium of medical leaders in the United Kingdom, has reiterated this philosophy by asserting that 'the patient must come first' [6]. Giving this priority to the health and well-being, or good, of the patient is broadly consistent with the ethos of patient-centred care. Although patient-centred care has sometimes been described as recognizing the personhood of the clinician, this latter concept has been underdeveloped in most accounts of patient-centred care [12], which hold the interests of the clinician as secondary $[5]$.

Reproducing a lithograph from the Norwegian, symbolist artist, Edvard Munch, Figure 1 therefore depicts patient-centred care as an artistic image of high contrast.

\section{Figure 1. Jaloezie II (Jealousy), 1896, Edvard Munch*}

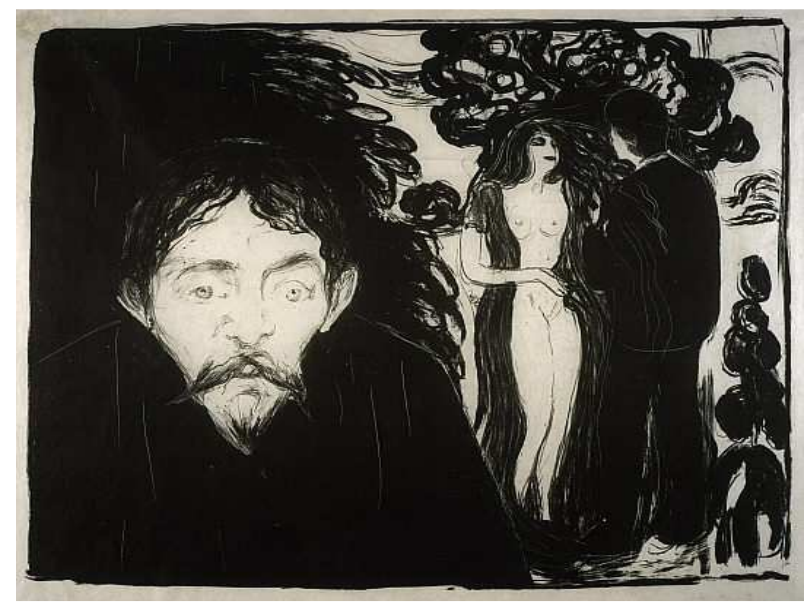

In my re-interpretation of this image (that the artist produced to portray the vice of jealousy) the young couple, exposed in direct light, signifies the patients. The clinician is in darkness. In these lighting conditions they can see themselves, but cannot see the clinician. In comparison, the clinician could see them if he wanted to, but he cannot easily see himself. Instead, he stands alone, isolated and apparently reluctant to leave the shadow that obscures his own presence and draws attention to the patients. Yet the clinician has a dominating and pervasive influence to the extent that the choices available to the patients dwell within the shadow, which can be seen as a metaphor of his power over their relationship [10].

Four main problems weaken patient-centred care, as so depicted, in theory and practice. First, the personhood of the patient is implicit. Patient-centred care illuminates the patient, rather than the person, through its patient-centred nomenclature. Who the patient is can also be unclear. Although invariably seen to be the individual attending for care, the patient frequently includes others, who are rendered (in)visible by the light or shadow cast by informal caregivers and who attend with, or for, the person receiving care; the family of that person; or indeed the whole population. Similarly, it is not always clear which clinician has overall responsibility for the clinical care being planned and/or provided.

Second, the personhood of the clinician is seldom recognized, as noted above. The patient-centred clinician gives priority to patient interests, which are now balanced against the interests of populations through affective neutrality, rational action and detached concern. Absent, therefore, is the light needed to illuminate and expose the clinician as a person whose personal interests exists behind this professional persona. Those interests of clinicians might include how to manage their own emotions and moral problems, which can arise in caring for patients and themselves [17]. In contrast to Zaner [18], I doubt that such interests are sufficiently visible in the primary relationship of clinicians and patients and I disagree that the interests of clinicians are subordinate to, or independent of, patients' interests [19]. Altruism that devalues the interests of clinicians, disrespects patients and clinicians since the interests of both parties are interdependent. Acting only for the sake of the patient produces 'a replicative, not a productive, focus ... [which turns] a dialogue into a monologue by focusing on only one of the selves engaged in the relation' [20].

Third, principles such as the primacy of the patient invite legalistic rule-following. More important, I believe, than working within the a priori rules of patient-centred care, and meeting the obligations they impose, is the concrete need for both the patient and clinician to give and receive care in order to hold and promote mutual well being. Their mutual good life requires attention to the context of the personal meaning and perceived significance of the particulars of their relationship with themselves and indeed each other. This significance is co-constituted phenomenologically by the clinician and patient actively participating in, and having first person experience and understanding of, each case at hand.

Fourth, despite signifying a conceptual advance on disease-centred and clinician-centred models [11], patient- 
centred care has not proven able, in practice, to resist the countervailing forces referred to in the Introduction. It has been quite unable to prevent biomedicine from reducing sick patients to diseased body machines or diseased body parts and attempting to fix what is broken according to the authority and dictates of knowledge based on the natural sciences. Evidence-based medicine and whole population care underlie the rise of these practices. By standardizing clinical practice, making clinicians into state agents whose professional autonomy recedes into dark shadows and reducing patients to normative objects of biometric measurement, they miss the needs and interests of patients and clinicians qua subjectively embodied, human individuals who personally and uniquely experience their own and others' illness symptoms, distress and suffering [14]. It is hardly surprising, therefore, that clinicians are frequently depicted as co-terminous with mind ... [and] notoriously disembodied' [21] and little more than paid service providers [22,23]. Threatening patient-centred care has been the light of evidence-based care and population care, which has been projected so brightly behind patients and clinicians that both of these parties have frequently come to be visible only as anonymous silhouettes cast in the performative role of shadow puppets.

A fundamental cause is that medicine is disingenuous. Despite the rhetoric of patient-centred care, medicine continues to promote clinician-centred concepts such as medical error [24], provider continuity [25] and pay-forperformance [26], typically in the context of evidencebased clinical decision-making that aims to inject more epidemiology into clinical practice [2]. Such concepts expose an underlying mistrust, not only in the professional autonomy of clinicians who are nevertheless held responsible for patients, but also in the capacity of patients to co-produce health care, all of which contradicts the cosmetic use of biopsychosocial language, such as patientcentred care. Even the Doctor-Patient Relationship Special Interest Group of the North American Primary Care Research Group [27] appears tainted in defining the doctor-patient relationship as 'the interface where physicians' clinical knowledge and skill are translated into the care of the patient.' If patient-centred care does not intend to devalue clinician interests, it should say what it means. It cannot reasonably protest, like Alice in Wonderland, 'I do ... at least - at least I mean what I say that's the same thing, you know' [28].

\section{Relationship-centred care}

In response to such limitations of patient-centred care, the model of relationship-centred care [12] illuminates the central role and immediate importance of human relationships in health care. These relationships include a clinician-patient relationship that respects the personhood and partnership of the clinician and patient. Relationshipcentred care achieves this enlightenment in two ways.
First, by emphasising the role of relationships, it helps to explicate how care takes place. Second, it reconceptualizes relationships as complex responsive processes. These processes are ones that account for continuously self-organising patterns of meaning in social interactions, which make key dimensions of the relationship process visible. Such dimensions include unintended and non-linear information transfer, which contradict standard ways of understsanding communication, relationships and care [29].

Relationship-centred care exposes human vulnerability as important information in the social spaces that people inhabit. In theory, therefore, it banishes to shadow the practice - when not freely chosen - of emotional detachment among clinicians [30] [31]. In contrast to the emotional labour of clinical empathy that involves 'deep and surface acting', I am referring here to a cathartic expression of self in the context of helping to relieve the clinician of 'unrealistic expectations of control and their constant shadow' [29]. In these terms, relationship-centred care aims to protect the well-being of the clinician and patient as individual moral agents in the context of reciprocal influence. However, recent attempts to fuse patient-centred care and relationship-centred care into patient and relationship-centred care (PRCC) make no sense because in practice these models vary greatly in their commitment to the personhood of clinicians. Conflating the models confuses their identities, questions the commitment of relationship-centred care to the personhood of the clinician and negates the raison d'être for relationship-centred care. In addition, relationship-centred care tends to subordinate health outcomes to how care takes place through human relationships, which carries two key limitations. First, relationships take place not only between people, but also among things like rules and procedures [18]. Second, relationships are a necessary, but not sufficient, criterion of the quality of care, even when clinicians and patients can get to know one another as people. In particular, the effectiveness of clinical or technical care is left unhighlighted in shadow [32].

\section{Concept of a 'window mirror'}

Glyn Elwyn and I concurrently developed a variation of this last model. This variation is more holistic and egalitarian than relationship-centred care. It uses the concept of a 'window mirror' to emphasize in its simplest form the interdependent and equal moral interests of the patient and clinician in their dyadic coproduction of care. To understand this concept, the reader is invited to imagine himself inside his home at night standing next to a clear window. If it is dark inside the room, but light outside, he will be able to see through the window. If it is light inside, but dark outside, he will see his reflection in the window. If the light is of equal intensity on both sides of the window, he will be able to see through the window and see 
his reflection in the window. Figure 2 depicts this window mirror effect of the reader seeing the other person and himself at the same time to meet the equal moral interest of the clinician and patient in caring equally about themselves and each other as people.

\section{Figure 2. The clinician-patient relationship as a window mirror}

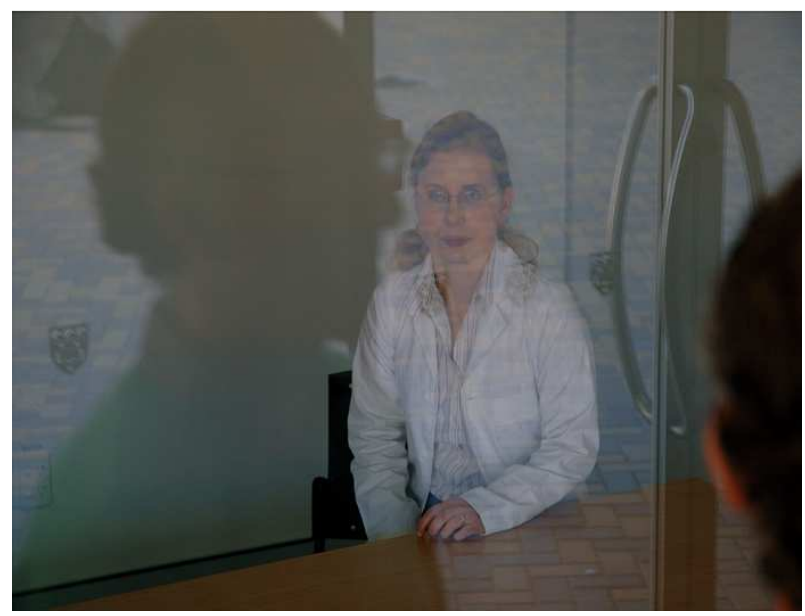

Patients do not always have the same capacity and power as clinicians to alternate their focus or the provision of care. However, the clinician and patient are morally entitled, and hence obligated, to care and be cared about [10], as best they can, and then to benefit from the care that they co-produce within their interrelationship [33]. Moreover, as people, they each feel a need to care about the other person as well as themselves. Levinas suggested that the 'other' casts a shadow on our possession of the world, calling us out to face their suffering, and it is in recognizing our exile in the world that we become capable of caring for the other [34]. Thus, in the window mirror 'each and every person receives full and equal recognition of their uniqueness' [35].

Yet how can clinicians and patients dwell constantly in the window mirror? How can their natural attitude be toward their interdependent interests in care? An answer is found in the visual encounter. Constructed as an experience of perceiving or interpreting, rather than as a totalizing experience of seeing only in an optical sense, vision reveals that the eyes of the clinician and patient are also window mirrors (Figure 3). As physical features, they can represent what is visible, yet also 'allow for the revelation of that which eludes vision's grasp ... and take us to the invisible'. For example, the eyes - or actually the 'look' - of the other person [36] can help us to access their inner self, for example, by observing their surprise (eyes widen), happiness (eyes glow) or interest and cognitive workload (eyes dilate). Plato's Phaedrus [37] thus refers to 'the eyes which are the windows of the soul'; and the French declare, 'Les yeux sont le miroir de l'dme': the eyes are the mirror of the soul.
In turn, a visual encounter with the eyes of the other person can reveal our own reflection. Even if we cannot see it, our reflection is there in the meeting of the eyes. What this signifies to us depends on our perspective. From a Cartesian viewpoint, we do not see ourselves. What is reflected is an 'outside', a 'dummy' [38], an 'expressive envelope'[39]. So, Cartesian clinicians do not look into the eyes of the patient to see themselves seeing or gain a sense of self. They objectify the reflected physical body, detaching it from the clinical encounter. In contrast, a phenomenological perspective is based on a description of how things appear outside the world of objects. For example, Merleau-Ponty [40] contends that instead of having a body whose image we construct in our minds, we are the body through which we know and access the world. As this body, which can think and perceive, we 'see' ourselves and are seen by the other person [41] [39]. We and they are inseparable in this perceptual experience of reciprocal openness and togetherness. Without prior thought or conceptualisation, that experience produces care. In the window mirror of the eyes of the other person, we see ourselves already in them. However, this interpretation contrasts with the Cartesian distinction between 'I and you'; with some conceptions of empathy, such as: 'I am you' or at least 'I might be you' [42] when 'you lay aside yourself' [43]; and with the postmodern concept of 'arche-health' [44], which resists and dissolves the identities of the clinician and patient. Each member of the dyad is unique in the window mirror, but is not isolated and cannot be parted.

\section{Figure 3. The 'window mirror' of the eyes}

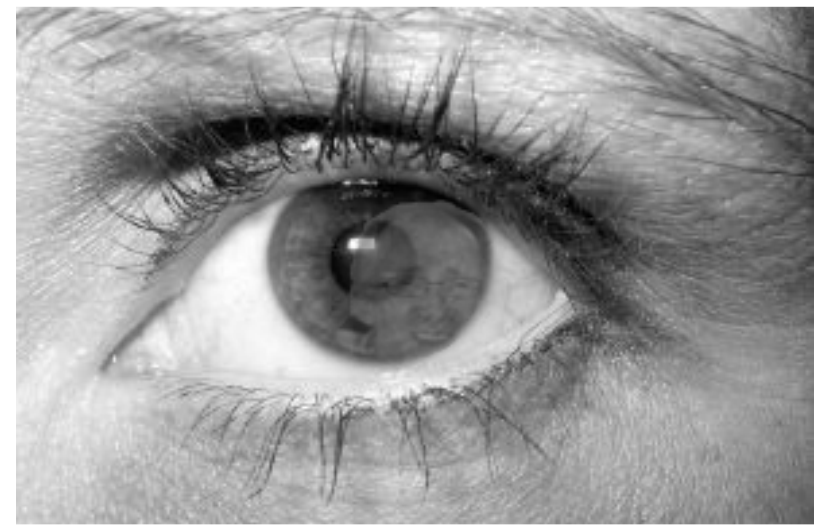

Achieving this representation of interdependent care as a 'window mirror' does not remove the spotlight from the patient. Rather, the model enlarges and diffuses this light on and beyond the patient, so as to soften its illumination. In so doing, it removes the shadows cast, for example by the other person, by health professionalism and by modern medicine. The illumination produces no shadow, because light of equal intensity reaches the patient and clinician from all directions [45] to expose the equal consideration of their equal and discernable moral interests. Just as the 
clinician loses his shadow in patient-centred care, so too for a different reason do the clinician and patient lose the shadows that manifest in the abstraction of the "window mirror'.

This loss is problematic. Allegories such as The Shadow [46] Peter Pan [47] reveal that to be without a shadow is unnatural and transgresses social norms. As a normal part of bodily wholeness, visible shadows help us to see ourselves as embodied. They are an external validation of our bodily existence and draw the attention of other people to our illuminated selves. Shadows therefore are necessary to being a person and seeing the world. When Peter Pan lost his shadow through a window, Wendy came to the rescue. 'I saved your shadow for you,' she comforted Peter, because '... one can't leave his shadow lying about and not miss it sooner or later' [47]. Personcentred care succeeds in finding and reattaching the missing shadows of the clinician and patient.

\section{Person-centred care}

Person-centred care is no less holistic, but also more realistic and pragmatic, than the ideal of care as a 'window mirror'. Person-centred care is care of, and by, persons, whom I wish to define as individuals whose degree of selfconsciousness entitles them to maximal moral standing in their population [48]. These illimitable, ever-changing individuals, who may include patients or clinicians, are ends rather than merely means. They have the capacity to flourish as co-producers of care on the basis of their moral agency over - and responsibility for - the choices they make, such as treatment decisions and the meanings of the experiences they live [49,50]. In an environment of continuing health care, centring care delivery on sick people looks explicitly therefore to get close 'to the individualized person [before we know their illnesses] in all of his or her levels of being and contexts' [51]. Accordingly, this care exposes people as whole persons, since each of their contexts is a whole in signifying 'a system of multiple interrelationships among constituents' [18].

Requiring light and shadow, the wholeness of personcentred care recognizes the metaphysical significance of both what is illuminated and what dwells in shadow. Being or becoming a whole person involves the interplay of light and shadow at two, interrelated levels. The first level takes place within the person. It refers to the interiority and particularity of the subjective experience of the person, whether the person behind the disease (including the integration of the disease, or body, with the mind and spirit) or the person behind the person, whom the person may come to recognize and reveal details and insights about, to themselves and others. The public face of this person is the visible persona, a social mask. Personcentred care can help people to de-mask themselves to themselves by turning inward the light in order to look beneath the surface, for example, through psychotherapy and guided introspection, but always against the backdrop of the community of which they are part. It can help these people to discern and recognize, in the light or softened shadow, an essential, unchanging self [52,53], an emergent self that they continually (re)construct [54], or 'no self' [55]. Plato went further in suggesting that people see only shadow-objects of a higher reality, and Martin Luther King Junior similarly opined that, 'everything we see is a shadow cast by that which we do not see.' Knowledge of the person within is always incomplete, making the persona itself a kind of shadow, but shadows, which need not be malevolent [47], depend on light to reveal their existence.

Second, integral to being or becoming a whole person, is the exteriority of individuals' engagement with each other and with the lived, external environment [56], including family, the community and the whole population [57], as these relationships appear in the mind. As the Xhosa proverb explains [58], umuntu ngumuntu ngabantu; a person is [and becomes] a person through persons. People are social creatures who need strong relationships with other people in order to be whole, for example, by dignifying themselves in the eyes of these others. Such relationships provide a social context within which people can penetrate and understand, without reflection, the nakedness of 'that part of the other that escapes the visible exteriority of the world' (cf Figure 1). The clinician and patient can thus look beyond the appearance of the other person [34] and do things with and for them in order to give their own lives a meaning or purpose beyond themselves.

In these terms, person-centred care transcends what is outwardly visible by drawing attention to the inner, hidden space that the invisible shadow side of the self and other person occupies. Having softened and looked into this shadow, individuals can integrate it with their external selves. Once individuals 'befriend' their shadow, they become free to share it (or not) with others, for example by displaying emotions while retaining a distinction between being at once either a clinician or a patient. It follows that person-centred care shows respect, in clinical practice, for the integration of science and art in order to reconcile the objectives of cure and care, one neither more nor less important than the other [13]. Clinicians and patients will only be able and willing to co-create this respect when their society cultivates human virtues such as humanity (or doing more than the right thing by others) to make visible and safe the revelation of hidden or underexposed shadows [35].

Modern photography offers insights into how personcentred care may expose and integrate areas of light and shadow. Just as high dynamic range photography combines the best parts of bright and dark images into single photographs (and adjusts the tonal range), so too does person-centred care illuminate an inclusive space in which to sharpen engagement with issues that are clearly exposed and those that otherwise are underexposed in dark 
shadow [59]. An example of health record keeping illustrates concretely how this engagement can integrate the different interests and perspectives of the clinician and patient, as well as clinical care and interpersonal care. Just as clinicians can best deliver and record scientific and technical components of care, so too may competent patients optimally reflect on, and record details of, their own illness 'story' in their own voice. This narrative voice, which can all-too-easily be missed, can express what counts as experience and specify how, in the context of patients' values, beliefs, needs, preferences, intentions and questions, it has meaning and significance for them beyond the clinical perspective of the clinician [60]. In turn, clinical records can provide the latter perspective and a shadow narrative of clinician self-care, for example, through evidence of a balanced patient load and taking daily breaks and holidays. Patient regard for the clinician can be indicated through patients documenting realistic expectations of their clinician and their appreciation for the care that the clinician provides.

To some extent, the perspectives of patients on their main life problems [61] and the help they want with lifestyle and mental health, have already begun to be integrated into person-centred clinical care delivery through the combined use of narrative medicine and clinical records [62]. However, there is scope for such integration to increase. Just as software can now combine differently exposed photographs to optimize the light range of tonal values, so too could new information and communication technologies for health care delivery (the so-called e-health technologies) be developed to maximize the data capture of an expanded and dynamic range of clinician and patient perspectives in order to facilitate their focused comparison. This comparison could expose levels of understanding and agreement on the nature, meaning and significance of health problems and treatments; aid joint decision-making, for example through bridging, which is an approach to negotiation that protects the ability of individuals to satisfy their most important interests without a need for compromise [63, 64]; and optimize the potential net benefits of the health care delivery. However, these different outcomes assume, among other things, a spirit of cooperation; an openness to learn from a dynamic and inclusive range of perspectives and the narrative competence of clinicians to expose and integrate clinical evidence and patients' stories into individualized, patient care plans to which the patient is willing and able to adhere [65].

\section{Conclusion}

In appropriate lighting, the patient and clinician can each be clearly discerned as whole persons who, within the limits of their different capacities, are able to co-provide care of mutual benefit [33]. At least in the context of continuing clinician-patient relationships, such as which characterize primary care, the model of person-centred care maximizes the range of illumination in which the clinician and patient can see themselves and each other as socially interacting individuals in the population. By exposing de-emphasized areas of lightened shadow, without over brightening and losing detail in the parts already visible, person-centred care can capture an expanded range of information and thereby optimize health care delivery. Although this conclusion may appear deceptively simple, it has only recently become salient through the inability of other models of the clinicianpatient relationship to satisfy clinician and patient interests in giving and receiving care of mutual benefit.

\section{References}

[1] Weatherall, J. (2009) The epistemically virtuous clinician. Theoretical Medicine and Bioethics 30, 249-265.

[2] Buetow, S., Upshur R., Miles A., Loughlin M. (2006) Taking stock of evidence-based medicine: Opportunities for its continuing evolution. Journal of Evaluation in Clinical Practice 12, 399-404.

[3] Buetow, S., Docherty B. (2005) The seduction of general practice and illegitimate birth of an expanded role in population health care. Journal of Evaluation in Clinical Practice 11, 397404.

[4] Gruen, R., Campbell E., Blumenthal D. (2006) Public roles of US physicians. Journal of the American Medical Association 296, 2467-2475.

[5] ABIM Foundation ACP-ASIM Foundation, European Federation of Internal Medicine. (2002) Medical professionalism in the new millennium: a physician charter Annals of Internal Medicine 136, 243-246.

[6] Medical Schools Council. The Consensus Statement on the Role of the Doctor 2008.

http://www.medschools.ac.uk/AboutUs/Projects/Documents/Role $\% 20$ of\%20Doctor\%20Consensus\%20Statement.pdf (accessed 8 February 2011).

[7] Stewart, M., Brown J. B., Weston W. W., McWhinney I. R., McWilliam C. L., Freeman T. R., eds. (1995) Patient-Centered Medicine. Transforming the clinical method. Thousand Oaks: Sage Publications.

[8] Mead, N., Bower P. (2000) Patient-centredness: a conceptual framework and review of the empirical literature. Social Science \& Medicine 51, 1087-1110.

[9] Stewart, M. (2001) Towards a global definition of patient centred care. British Medical Journal 322, 444-445.

[10] Buetow, S., Elwyn G. (2008) The window mirror: a new model of the patient-physician relationship. Open Medicine 2, (1), E20-25.

[11] Marcum, J. (2008) Humanizing Modern Medicine: An Introductory Philosophy of Medicine. Dordrecht: Springer.

[12] Beach, M., Inui T., Relationship-Centered Care Research Network. (2006) Relationship-centered care: a constructive reframing. Journal of General Internal Medicine 21, (s1), S3-S8. [13] Miles, A. (2009) On a Medicine of the Whole Person: away from scientistic reductionism and towards the embrace of the complex in clinical practice. Journal of Evaluation in Clinical Practice 15, 941-949. 
[14] Mezzich, J., Snaedal J., Van Weel C., Heath I. (2010) Toward person-centred medicine: From disease to patient to person. Mount Sinai Journal of Medicine 77, 304-306.

[15] Sorenson, R. (2008) Seeing Dark Things. The Philosophy of Shadows. Oxford: Oxford University Press.

[16] Nowak, J. (2010) Out from behind the shadows. Philosophy Today 54, (3), 265-278.

[17] Barnard, D. (1998) Love and Death: Existential dimensions of physicians' difficulties with moral problems. Journal of Medicine and Philosophy 13, 393-409.

[18] Zaner, R. (1993) Voices and time: The venture of clinical ethics. Journal of Medicine and Philosophy 18, 9-31.

[19] Barilan, Y. (2009) Responsibility as a meta-virtue: truthtelling, deliberation and wisdom in medical professionalism. Journal of Medical Ethics 35, 153-158.

[20] Edwards, K. (2001) Critiquing empathy. Second Opinion 4, 35-47.

[21] Mohrmann, M. (2001) Human frailty and the burden of medicine: a medical response. The Hedgehog Review 3, (2 (Summer)), 38-45.

[22] Zealberg, J. (1999) The Depersonalization of Health Care. Psychiatry 50, (3), 327-329.

[23] Elwyn, G., Buetow, S., Hibbard, J., Wensing, M. (2007) Respecting the subjective: quality measurement from the patient's perspective. British Medical Journal 335, 1021-1022.

[24] Buetow, S., Elwyn G. (2007) Patients and errors: a dangerous combination. Lancet 369, 158-161.

[25] Buetow, S. (2004) Towards a new understanding of provider continuity. Annals of Family Medicine 2, 509-511.

[26] Buetow, S., Elwyn G. (2007) Patient performance standards: the next bold policy initiative in health care? Journal of Health Services Research and Policy 12, 48-53.

[27] Anonymous. Doctor-patient relationship SIG: North American Primary Care Research Group, 2010; available at http://www.napcrg.org/about/docpatientsig.cfm

[28] Caroll, L. (1983) Alice in Wonderland. London: Dent.

[29] Suchman, A. (2006) A new theoretical foundation for relationship-centered care. Journal of General Internal Medicine 21, S40-S44.

[30] Osler, W. (1925) Aequanimitas. With other Addresses to Medical Students, Nurses and Practitioners of Medicine. 2nd ed. Philadelphia: Blakiston's Son and Co.

[31] Sa Couto, J. (2007) Family medicine should shift attention from rationality to emotions: Negative position. In: Ideological Debates in Family Medicine. (eds. S. Buetow, T. Kenealy), pp. 173-179. New York: Nova Biomedical.

[32] Campbell, S., Roland M., Buetow S. (2000) Defining quality of care. Social Science and Medicine 51, 1611-1625.

[33] Buetow, S. (2005) To care is to coprovide. Annals of Family Medicine 3, 553-555.

[34] Doukhan, A. (2010) From exile to hospitality. A key to the philosophy of Emmanuel Levinas. Philosophy Today 54, (3), 235-246.

[35] Potter, A. (2010) The Authenticity Hoax. Melbourne: Scribe. [36] 36. Sartre, J. (1958) Being and Nothingness. London: Routledge.

[37] Jowett, B. Plato Phaedrus 1999: Part two of three webpage parts, 1999; available at http://evansexperientialism.freewebspace.com/ plato_phaedrus02.htm

[38] Merleau-Ponty, M. (1964) Eye and mind (trans. C. Dallery). In: The Primacy of Perception. (ed. J.E. Edie), pp. 159-192. Evanston, Illinois: Northwestern University Press.
[39] Mackie, F. (2005) Seeing oneself in the mirror: critical reflections on the visual experience of the reflected self. Journal of Phenomenological Psychology 36, 21-43.

[40] Merleau-Ponty, M., ed. (1962) (trans. C. Smith). Phenomenology of Perception. New York: Humanities Press.

[41] Moran, D. (2000) Introduction to Phenomenology. London: Routledge.

[42] Spiro, H. (1992) What is empathy and can it be taught? Annals of Internal Medicine 116, 843-846.

[43] Rogers, C. (1980) A Way of Being. Boston: Houghton Mifflin.

[44] Fox, N. (1999) Postmodern reflections on 'risk', hazards' and 'life choices'. In: Risk and sociocultural theory: New directions and perspectives. (ed. D. Lupton D), pp. 12-33. Cambridge: Cambridge University Press.

[45] Wildi, E. (2008) The Hasselblad Manual. 7th ed. Oxford: Focal Press.

[46] Andersen, H. The Complete Fairy Tales and Stories. New York: New York.

[47] Barrie, J. (1987) Peter Pan. London: Penguin.

[48] Walters, J. (1997) What is a person? Champaign, Il: University of Illinois Press.

[49] May, C., Purkis M. (1997) Editorial: exploring relationships between professionals, patients and others. Health and Social Care in the Community 5, (1), 1-2.

[50] McMillan, R. (1995) Responsibility to or for in the physician-patient relationship. Journal of Medical Ethics 21, 112-115.

[51] Schaffner, K. (2010) The person and philosophy of science and medicine. International Journal of Integrated Care 10, 4447.

[52] De Grazia, D. (2005) Enhancement technologies and human identity. Journal of Medicine and Philosophy 30, 261-283.

[53] Stevenson, F., Knudsen P. (2008) Discourses of agency and the search for the authentic self: The case of mood-modifying medicines. Social Science \& Medicine 66, 170-181.

[54] Flanagan, O. (1992) Consciousness Reconsidered. Cambridge, MA: MIT Press.

[55] Metzinger, T. (2003) Being No One. Cambridge, MA: MIT Press.

[56] Tauber, A. (2000) Confessions of a medicine man. An essay in popular philosophy. Cambridge, Mass: MIT Press.

[57] Buetow, S., Getz L., Adams P. (2008) Individualised population care: linking personal care to population care in general practice. Journal of Evaluation in Clinical Practice 14, 761-766.

[58] Shutte, A. (1993) Philosophy for Africa. Rondebosch: South Africa: UCT Press.

[59] Greene, J. (2007) Mixed methods in social inquiry. San Francisco: Wiley.

[60] Wiggins, O., Schwartz M. (2005) Richard Zaner's phenomenology of the clinical encounter. Theoretical Medicine 26, 73-87.

[61] Battersby, M., South Australia HealthPlus Team. (2205) Health reform through coordinated care: SA HealthPlus. British Medical Journal 330, 662-666.

[62] Goodyear-Smith, F., Arroll B., Coupe N. (2009) Asking for help is helpful: Validation of a brief lifestyle and mood assessment tool in primary health care. Annals of Family Medicine 7, 239-244.

[63] Pruitt, D. G. (1981) Negotiation Behaviour. New York: Academic Press.

The International Journal of Person Centered Medicine Volume 1 Issue 1 pp 196-203 
[64] Buetow, S. (1998) Four strategies for negotiated care. Journal of the Royal Society of Medicine 91, 199-201.[65] Charon, R. (2006) Narrative medicine: Honoring the stories of illness. New York: Oxford University Press.

\section{* HARVARD ART MUSEUMS}

Images may be reproduced only under conditions described in the Permission Agreement (reference \# 11- H2291) and should include the following credit information (please note minimum required information listed in BOLD). Any other use, reproduction, or distribution is prohibited

For questions or further information (including information about file specifications, color management, and copyright), please contact DIVR, Harvard Art Museum, 32 Quincy Street,
Cambridge, MA 02138 (phone: 617 -495-2389, fax: 617-4952990, email: am divr@fas.harvard.edu).

IMAGE CREDIT INFORMATION

Image Number: DDC111802 Accession Number: M20225 Artist: Edvard Munch Title: Jealousy

Date: 1896 Medium/Support: Dimensions: 46.3 x 55.8 cm (18 1/4 x 21 15/16 in.)

Credit Line: Harvard Art Museums/Fogg Museum, Purchase through the generosity of Lynn and Philip A. Straus, Class of 1937, M20225 Copyright: Art (C) The Educational Alliance, Inc./Estate of Peter Blume/Licensed by VAGA, New York, NY Photo: Imaging Department (C) President and Fellows of Harvard College 